\title{
Tumor Findings Specimen Condition
}

National Cancer Institute

\section{Source}

National Cancer Institute. Tumor Findings Specimen Condition. NCI Thesaurus. Code

C119939.

A characteristic that refers to the physical and org anoleptic state of a biospecimen used for a tumor findings assessment. 